\title{
Renal Resistive Index as One of The Predictors of Cardiac Diastolic Dysfunction in Type 2 Diabetic Patients \\ Hend M. Abdelhakam ${ }^{1 *}$, Ehab M. Moussa ${ }^{2}$, Salah Argoon ${ }^{3}$, Mahmoud Ashry ${ }^{4}$ \\ Departments of ${ }^{1}$ Internal Medicine, SVU, Qena, ${ }^{2}$ Radiology, Assiut University, Assiut, ${ }^{3}$ Internal Medicine (Endocrinology Unit), Assiut University, Assiut, \\ ${ }^{4}$ Internal Medicine (Cardiology and Critical Care Unit), Assiut University, Assiut, Egypt \\ *Corresponding Author: Hend M. Abdelhakam, Email: Hendhakam@ gmail.com, Phone: +0201003161920
}

\begin{abstract}
Background: Renal resistive index (RRI) is markedly affected by renal and systemic conditions. Aortic stiffness with affected pulse pressure in type 2 diabetic patients is associated with backward overload effect on the heart. This had led to consider RRI as a preferred marker for prediction of an increased total cardiovascular risk.
\end{abstract}

Aim: This study interested in detecting the relationship between the renal resistive index and the cardiac diastolic dysfunction in individuals with type 2 diabetes.

Patients and methods: A hospital based, cross-sectional study was conducted on 79 type 2 diabetic patients with no symptoms of cardiovascular involvement. They were subjected to echocardiographic evaluation of diastolic dysfunction and renal duplex for measurement of RRI.

Results: The results of the current study revealed a significant relationship between renal resistive index and diastolic dysfunction $(\mathrm{p}<0.001)$.

Conclusion: Worsening indices of diastolic function in subjects with type 2 diabetes paralleled increases in RRI, which was detected as one of the independent predictors of diastolic dysfunction in these results.

Keywords: Diastolic Dysfunction, Renal Resistive Index, Type 2 DM.

\section{INTRODUCTION}

Renal resistive index (RRI) is markedly affected by renal and systemic conditions ${ }^{(\mathbf{1})}$. RRI gives prognostic information regarding micro and macroangiopathy ${ }^{(2)}$. The role of RRI is not limited to detection of renal arteriosclerosis, there is growing evidence demonstrated that RRI has many intra and extra renal determinants and is associated with increase of cardiovascular morbidity ${ }^{(3)}$. Attempts to reduce cardiac morbidity and mortality in type 2 diabetic patients focus on cardio-renal pathophysiology and new risk factors other than conventional factors and this was the aim of our research.

\section{PATIENTS AND METHODS}

A hospital based, cross-sectional study was conducted on 79 patients known to have type 2 diabetes mellitus (DM), and who clinically had $\mathbf{H h}$ symptoms of cardiovascular involvement (with normal ECG). The recruited patients were selected from those attending the Diabetes Clinics at the Endocrine Centre, Assiut University hospitals.

Patients with type $1 \mathrm{DM}$, other cardiac diseases (valvular heart disease, ischemic • cardiomyopathy) and congestive heart failure or end organ failure were excluded from the study. The study was conducted in the period from March, 2017 to December, 2019.

\section{Ethical consideration}

Research Ethics Committee approved the research protocol on 19/11/2014 under number
17200358 and an informed consent was obtained from each participant.

Procedure: The patients were subjected to full history taking and clinical examination including fundus examination supported by relevant investigations. The following were carried out:

\section{Baseline Data}

- Information obtained using a questionnaire included: sex, age, consanguinity (first-degree relatives), history of diabetes, premature cardiovascular events, dyslipidemia, hypertension, smoking habits, any other diseases and the use of current medications including antidiabetics (oral glucose-lowering medications and/or insulin), lipid-regulating agents and antihypertensive drugs.

\section{Imaging and Laboratory Investigations}

Blood glucose levels (FBG, RBG), HbA1C, lipid profile, renal function tests and the electrolytes, urine routine and microscopy, estimated glomerular filtration rate, and chest x-ray.

Transthoracic echocardiogram (TTE) was performed by (Philips Medical Systems, Bothell, Washington, USA, 3.5 Mhz transducer) in the left lateral decubitus position. Recordings and measurements were obtained according to standardized echocardiography parameters. Left ventricular diastolic dysfunction (DD) was divided into grade I (impaired LV relaxation), grade II (pseudo-normal filling pattern) and grade III (restrictive filling pattern) ${ }^{(4)}$. 
- Measurement of RRI: The renal Doppler assessment (by $3.5 \mathrm{MHz}$ deep probe, HDI 5000 instrument, Philips Medical Systems, Bothell, Washington, USA) was done. The renal resistance index (RRI) was calculated as: the peak systolic velocity - end diastolic velocity/peak systolic velocity. Individuals with an RI > 0.7 were said to have increased RRI.

\section{Statistical analysis}

Data were verified, coded by the researcher and analyzed using IBM-SPSS 21.0 (IBM-SPSS Inc., Chicago, IL, USA). Descriptive statistics: Means, standard deviations (SD), medians, ranges and percentages were calculated. Test of significances: Odds ratio (OR) (univariate analyses) was used to detect significance. The clinical and demographic factors with proven statistical significance from the univariate analyses were further included in the multivariate logistic regression models. A significant $\mathrm{p}$ value was considered significant when it is $\leq 0.05$.

\section{RESULTS}

Table (1) and (2) showed the baseline characteristics of the study cohort. The age of the participants had a mean of $51.7 \pm 7.6$ years old with males representing about $40 \%$ of the sample. Moreover, about one-quarter of the sample were smokers and the majority of the sample $(92 \%)$ were classified as overweight/obese according to BMI. For the clinical characteristics of the sample; diabetic disease duration ranged between 2 and 15 years with a mean of 7 years.

Almost half of the cases were on insulin treatment and had diabetic retinopathy, nephropathy or neuropathy. Also, about one-third of the sample had history of hypertension with only $10 \%$ with macrovascular complications.

Regarding laboratory investigations, blood sugar measurements were: FBS ranged between 70 and 600 with median of $180 \mathrm{mg} / \mathrm{dl}$, RBS had mean of $286 \pm 17 \mathrm{mg} / \mathrm{dl}$ and $\mathrm{HbA} 1 \mathrm{c}$ of $8.14 \pm 2 \mathrm{mmol}$. Kidney function tests were: bl. Urea was $23(11-35) \mathrm{mg} / \mathrm{dl}$ and S. creatinine was $1.3(0.5-7) \mathrm{mg} / \mathrm{dl}$. About twothirds had micro- or macro-albuminuria. The median GFR was 37 (31-181). The imaging data of the studied sample: About one quarter (24.1\%) had abnormal EF. Also, about two-thirds (65.8\%) of the sample had abnormal RRI.

Table (1): Demographic, clinical and some laboratory data

\begin{tabular}{|c|c|c|}
\hline Variable & Mean \pm SD & \\
\hline Age (years) & $51.67 \pm 7.6$ & \\
\hline Sex (Female) & $47(59.5 \%)$ & \\
\hline Smoking Status n (\%) & $21(26.6 \%)$ & \\
\hline Disease Duration (years) & $7.08 \pm 3.0$ & \\
\hline Insulin therapy $\mathrm{n}(\%)$ & $40(50.6 \%)$ & \\
\hline History of Hypertension $\mathrm{n}(\%)$ & $29(36.7 \%)$ & \\
\hline \multirow{3}{*}{ Blood Pressure } & SBP (mmhg) & $136.14 \pm 22.9$ \\
\hline & DBP (mmhg) & $80.13 \pm 17.6$ \\
\hline & PP (mmhg) & $56.27 \pm 16.5$ \\
\hline Waist Circumference $(\mathrm{cm})$ & $101.65 \pm 11.4$ & \\
\hline \multirow[t]{4}{*}{$\mathrm{BMI}(\mathrm{kg} / \mathrm{m} 2)$} & $32.54 \pm 4.4$ & \\
\hline & Normal: & $6(7.6 \%)$ \\
\hline & Overweight: & $20(25.3 \%)$ \\
\hline & Obese: & $53(67.1 \%)$ \\
\hline Macrovascular Complication n (\%) & $8(10.1 \%)$ & \\
\hline Diabetic Retinopathy n (\%) & $42(53.2 \%)$ & \\
\hline Diabetic Neuropathy n (\%) & $35(44.3 \%)$ & \\
\hline \multirow[t]{2}{*}{ Diabetic Nephropathy n (\%) } & Microalbuminuria & $37(46.8 \%)$ \\
\hline & Macroalbuminuria & $11(14 \%)$ \\
\hline $\operatorname{Egfr}(\mathrm{ml} / \mathrm{min} / \mathrm{m} 2)$ & $98.21 \pm 21.43$ & \\
\hline $\mathrm{FBG}(\mathrm{mg} / \mathrm{dl})$ & $112.32 \pm 12.87$ & \\
\hline $2 \mathrm{hs} \mathrm{PP}(\mathrm{mg} / \mathrm{dl})$ & $223.38 \pm 32.62$ & \\
\hline HbA1c (\%) & $8.14 \pm 2.0$ & \\
\hline Serum Creatinine $(\mathrm{mg} / \mathrm{dl})$ & $1.47 \pm 0.9$ & \\
\hline Urea (mg/dl) & $22.68 \pm 5.7$ & \\
\hline $\mathrm{TG}(\mathrm{mg} / \mathrm{dl})$ & $112.93 \pm 41.1$ & \\
\hline $\mathrm{LDL}(\mathrm{mg} / \mathrm{dl})$ & $139.07 \pm 38.8$ & \\
\hline HDL (mg/dl) & $63.55 \pm 11$ & \\
\hline
\end{tabular}

Values are expressed as the means \pm SD, number (percent).

n: Number, SD: Standard Deviation, h: Hour, SBP: Systolic Blood Pressure, DBP: Diastolic Blood Pressure, PP: Pulse Pressure, BMI: Body Mass Index, eGFR: estimated Glomerular Filtration Rate, FBG: Fasting Blood Glucose, 2hs PP: 2 hours Post Prandial, TG: Triglycerides, LDL: Low Density Lipoprotein, HDL: High Density Lipoprotein. 
ejhm.journals.ekb.eg

Table (2): Cardiac and Doppler imaging data of the studied sample

\begin{tabular}{|c|l|c|}
\hline Variable & \multicolumn{1}{|c|}{ Category } & $\mathbf{n}=\mathbf{7 9}$ \\
\hline \multirow{2}{*}{ Ejection Fraction (EF\%) } & Mean \pm SD & $58.28 \pm 8.4$ \\
\cline { 2 - 3 } & Median (Range) & $59(44-77)$ \\
\hline \multicolumn{2}{|c|}{ Abnormal EF $<\mathbf{5 0 \%}$} & $19(24.1 \%)$ \\
\hline \multirow{2}{*}{ Renal Resistance Index (RRI) } & Mean \pm SD & $0.98 \pm 0.1$ \\
\cline { 2 - 3 } & Median (Range) & $0.9(0.5-2.1)$ \\
\hline \multicolumn{2}{|c|}{ Abnormal RRI >0.7 } & $52(65.8 \%)$ \\
\hline Diastolic Dysfunction (DD) & No & $28(35.4 \%)$ \\
\cline { 2 - 3 } & G I & $36(45.6 \%)$ \\
\cline { 2 - 3 } & G II & $15(19 \%)$ \\
\hline
\end{tabular}

Table (3) and (4) demonstrated the univariate and multivariate logistic regression analysis for the significant factors affecting DD. After adjusting the age, the final model contained four predictors; BMI $(\mathrm{OR}=3.30,95 \% \mathrm{CI}: 1.04-9.67, \mathrm{p}=0.028), \mathrm{HbA1C}(\mathrm{OR}=1.48,95 \% \mathrm{CI}: 1.12-1.94, \mathrm{p}=0.005), \mathrm{RRI}(\mathrm{OR}=9.22$, 95\% CI: 1.19-28.12, $\mathrm{p}<0.001)$, Diabetic neuropathy ( $\mathrm{OR}=1.98,95 \%$ CI: 1.05-6.08, $\mathrm{p}=0.036)$.

Table (3): Significant factors affecting DD; univariate logistic regression analysis

\begin{tabular}{|l|c|c|c|}
\hline Factor & Odds Ratio & $\mathbf{9 5 \%}$ CI* & P-value \\
\hline Age ( years) & 1.004 & $0.912-1.051$ & 0.814 \\
\hline Sex (Male) & 1.082 & $0.684-4.215$ & 0.870 \\
\hline Smoker \% & 1.135 & $0.396-3.255$ & 0.701 \\
\hline BMI (> 25kg/m2) & $\mathbf{1 . 9 2 0}$ & $\mathbf{1 . 0 0 4}-\mathbf{6 . 5 8 1}$ & $\mathbf{0 . 0 4 4}$ \\
\hline Pulse Pressure (mm Hg) & 1.004 & $0.976-1.033$ & 0.770 \\
\hline Disease Duration/years & 0.983 & $0.844-1.145$ & 0.823 \\
\hline HbA1c \% & $\mathbf{2 . 3 2 5}$ & $\mathbf{1 . 1 4 8}-\mathbf{3 . 8 4 1}$ & $\mathbf{0 . 0 0 1}$ \\
\hline TGD mg/dl & 1.010 & $0.997-1.023$ & 0.134 \\
\hline LDL mg/dl & 1.008 & $0.912-1.051$ & 0.524 \\
\hline RRI & $\mathbf{6 . 0 7 6}$ & $\mathbf{1 . 1 5 0}-\mathbf{1 6 . 9 0 4}$ & $<\mathbf{0 . 0 0 1}$ \\
\hline Retinopathy & 0.975 & $0.387-2.475$ & 0.957 \\
\hline Neuropathy & $\mathbf{2 . 8 1 2}$ & $\mathbf{1 . 0 4 8}-\mathbf{7 . 5 4 8}$ & $\mathbf{0 . 0 4 0}$ \\
\hline Nephropathy & 1.521 & $0.602-3.842$ & 0.375 \\
\hline Macrovascular Complication & 1.733 & $0.326-9.222$ & 0.519 \\
\hline GFR (ml/min/m2) & 1.010 & $0.997-1.024$ & 0.145 \\
\hline
\end{tabular}

*: Confidence Interval

Table (4): Significant factors affecting DD; multivariable logistic regression analysis

\begin{tabular}{|l|c|c|c|}
\hline Factor & Odds Ratio & 95\% CI* & P-value \\
\hline Age & 0.981 & $0.924-1.043$ & 0.545 \\
\hline Sex (Male) & 1.630 & $0.633-4.193$ & 0.122 \\
\hline Smoker & 1.321 & $0.478-3.653$ & 0.245 \\
\hline BMI $(>\mathbf{2 5} \mathbf{~ k g / m 2 )}$ & $\mathbf{3 . 2 9 5}$ & $\mathbf{1 . 0 3 6}-\mathbf{9 . 6 7 1}$ & $\mathbf{0 . 0 2 8}$ \\
\hline HbA1c \% & $\mathbf{1 . 4 7 6}$ & $\mathbf{1 . 1 2 3}-\mathbf{1 . 9 4 1}$ & $\mathbf{0 . 0 0 5}$ \\
\hline RRI & $\mathbf{9 . 2 2 4}$ & $\mathbf{1 . 1 8 9}-\mathbf{2 8 . 1 2 3}$ & $<\mathbf{0 . 0 0 1}$ \\
\hline Neuropathy & $\mathbf{1 . 9 8 1}$ & $\mathbf{1 . 0 5 1}-\mathbf{6 . 0 7 8}$ & $\mathbf{0 . 0 3 6}$ \\
\hline
\end{tabular}

*: Confidence Interval 


\section{DISCUSSION}

In the current study, 79 patients with T2 DM who attended to the Outpatient Diabetes Clinics at the Endocrine Centre, Assiut University Hospitals were recruited.

Regarding the cardiac diastolic dysfunction, the percentage of the diabetic patients with DD was $65 \%$ (46\% with grade I, and $19 \%$ with grade II). This is consistent with Dikshit et al. ${ }^{(5)}$ who reported that $66 \%$ of diabetic patients had DD. Also, Ashour et al. ${ }^{(6)}$ found that $62 \%$ of asymptomatic diabetic patients had DD.

As regards disease characteristics, significant relationship was revealed between DD and diabetic neuropathy, which is in agreement with the results of Masugata et al. ${ }^{(7)}$, which was applied as case-control study on 77 normotensive diabetic patients and concluded that, cardiac DD without LV systolic dysfunction in patients with well-controlled type2 DM was significantly associated with diabetic neuropathy. In respect to the laboratory markers, it was found that $\mathrm{HbA} 1 \mathrm{C}$ was identified as independent predictor for DD, which is concordant with Patil et al. ${ }^{(8)}$ study that reported that alteration in $\mathrm{LV}$ diastolic function seems to be related to level of fasting blood sugar and $\mathrm{HbA1C}$ even within normal limits. In regard to RRI assessment: Bruno et al. (9) revealed that there was great vascular damage in patients with diabetes, and also suggested the usefulness of dynamic RRI assessment for the diagnosis of subclinical and diabetogenic vascular damage.

This is consistent with the results of this work as the percent of diabetic patients with RRI $>0.7$ was about $66 \%$. It seemed that the RRI dependence of blood glucose levels may be specific to medium-sized arteries such as intra-renal and orbital. The findings of Afsar $\boldsymbol{e t}$ al. ${ }^{\left({ }^{(10)}\right.}$ and Ohta et al. ${ }^{(11)}$ support the current findings, reporting a significant increase of RRI in DM. In addition, this study showed significant association between RRI and DD where it was considered as significant independent predictor for RRI. This is supported by MacIsaac et al. (12) who reported significantly higher RRI values in patients with echocardiographic markers of left ventricle diastolic dysfunction. It might be assumed that this relation stems from parallel organ damage of heart and kidneys in the course of type 2 diabetes.

\section{CONCLUSION AND RECOMMENDATION}

There is significant association of diastolic function in subjects with type 2 diabetes and the increases in renal resistive in sex as it was shown by our study that RRI is one of the important independent predictors of diastolic dysfunction. Based on the findings of the current study, it is recommended to have routinely evaluating RRI by renal duplex for type 2 diabetic patients for early assessment of subclinical diastolic dysfunction and early prevention of cardiac morbidities.

\section{STUDY LIMTATIONS}

The cross-sectional design of the study neither elucidate cause-and-effect relationships nor allowing generalizability of the results.

\section{REFERENCES}

1. Geraci G, Mulè G, Geraci C, Mogavero M, D'Ignoto F, Morreale M, Foraci AC, Cottone S (2015): Association of renal resistive index with aortic pulse wave velocity in hypertensive patients. Euro J Preventive Cardiol., 22 (4): 415-22.

2. Bruno RM, Salvati A, Barzacchi M, Raimo K, Taddei S, Ghiadoni L, Solini A (2015): Predictive value of dynamic renal resistive index (drin) for renal outcome in type 2 diabetes and essential hypertension: a prospective study. Cardiovascular Diabetology, 14 (1): 63-7.

3. Madero M, Peralta C, Katz R, Canada R, Fried L, Najjar S, Shlipak M, Simonsick E, Lakatta E, Patel K, Rifkin D, Hawkins M, Newman A, Sarnak M (2013): Association of arterial rigidity with incident kidney disease and kidney function decline: the Health ABC study. Clin J Am Soc Nephrol., 8: 424-33.

4. Grigorescu ED, Lacatusu CM, Floria M, Mihai BM, Cretu I, Sorodoc L (2019): Left ventricular diastolic dysfunction in type 2 diabetes - progress and perspectives. Diagnostics, 9 (3): 121-5.

5. Dikshit NM, Wadia PZ, Shukla DK (2013): Diastolic dysfunction in diabetes mellitus. National J Med Res., 3 (3): 249-52.

6. Ashour M, Elshobary ME, El-Shenody R, Kamil A-W, Abomohra AE-F (2019): Evaluation of a native oleaginous marine microalga Nannochloropsis oceanica for dual use in biodiesel production and aquaculture feed. Biomass and Bioenergy, 120: 439-47.

7. Masugata H, Senda S, Goda F, Yoshihara Y, Yoshikawa K, Fujita $\mathbf{N}$ et al. (2008): Left ventricular diastolic dysfunction in normotensive diabetic patients in various age strata. Diabetes Res Clin Practice, 79 (1): 91-6.

8. Patil VC, Shah KB, Vasani JD, Shetty P, Patil HV (2011): Diastolic dysfunction in asymptomatic type 2 diabetes mellitus with normal systolic function. Journal of Cardiovasc Dis Res., 2 (4): 213-22.

9. Bruno R, Daghini E, Landini L, Versari D, Salvati A, Santini E et al. (2011): Dynamic evaluation of renal resistive index in normoalbuminuric patients with newly diagnosed hypertension or type 2 diabetes. Diabetologia, 54 (9): 2430-9.

10. Afsar B, Elsurer R, Sezer S, Ozdemir FN (2010): Insulin resistance is associated with increased renal resistive index independent of other factors in newly diagnosed type 2 diabetes mellitus and hypertensive patients. Metabolism, 59 (2): 279-84.

11. Ohta $Y$, Fujii $K$, Ibayashi $S$, Matsumura $K$, Tsuchihashi T, Kitazono $T$ et al. (2008): Renal and carotid vascular resistance assessed with Doppler sonography. J Clin Ultrasound, 36 (2): 85-90.

12. MacIsaac RJ, Thomas MC, Panagiotopoulos S, Smith TJ, Hao H, Matthews DG et al. (2008): Association between intrarenal arterial resistance and diastolic dysfunction in type 2 diabetes. Cardiovasc Diabetol., 7 (1): 15-9. 